\title{
Distinct increased outliers among 136 rectal cancer patients assessed by $\mathrm{\gamma H} 2 \mathrm{AX}$
}

\author{
Jana Kroeber ${ }^{1 \dagger}$, Barbara Wenger ${ }^{1 \dagger}$, Manuela Schwegler ${ }^{1}$, Christoph Daniel ${ }^{2}$, Manfred Schmidt ${ }^{1}$, \\ Cholpon S Djuzenova ${ }^{3}$, Bülent Polat ${ }^{3}$, Michael Flentje $^{3}$, Rainer Fietkau ${ }^{1}$ and Luitpold V Distel ${ }^{1 *}$
}

\begin{abstract}
Background: In recent years attention has focused on $\mathrm{\gamma H} 2 \mathrm{AX}$ as a very sensitive double strand break indicator. It has been suggested that $\mathrm{H} 2 \mathrm{AX}$ might be able to predict individual radiosensitivity. Our aim was to study the induction and repair of DNA double strand breaks labelled by $\mathrm{YH} 2 \mathrm{AX}$ in a large cohort.

Methods: In a prospective study lymphocytes of 136 rectal cancer (RC) patients and 59 healthy individuals were ex vivo irradiated (IR) and initial DNA damage was compared to remaining DNA damage after 2 Gy and 24 hours repair time and preexisting DNA damage in unirradiated lymphocytes. Lymphocytes were immunostained with anti- $\gamma \mathrm{H} 2 \mathrm{AX}$ antibodies and microscopic images with an extended depth of field were acquired. $\gamma \mathrm{H} 2 \mathrm{AX}$ foci counting was performed using a semi-automatic image analysis software.

Results: Distinct increased values of preexisting and remaining $\mathrm{YH} 2 \mathrm{AX}$ foci in the group of $\mathrm{RC}$ patients were found compared to the healthy individuals. Additionally there are clear differences within the groups and there are outliers in about $12 \%$ of the RC patients after ex vivo IR.

Conclusions: The $\mathrm{YH} 2 \mathrm{AX}$ assay has the capability to identify a group of outliers which are most probably patients with increased radiosensitivity having the highest risk of suffering radiotherapy-related late sequelae.
\end{abstract}

Keywords: $\gamma \mathrm{H} 2 \mathrm{AX}$, DNA double strand breaks, Rectal cancer, Radiotherapy, Individual radiosensitivity

\section{Background}

In radiation therapy there is a need to find a monitoring assay which can predict a patients' individual radiosensitivity and the risk to develop early and late tissue reaction and to adjust the radiation dose when indicated. A pretreatment identification of cancer patients by a predictive assay of normal-tissue radiosensitivity may allow appropriate adjustment of treatment and could reduce the risk of therapy related side effects. Several different predictive assay strategies were tested, for review see [1].

To monitor the development of DNA double strand breaks (DSB) $\gamma \mathrm{H} 2 \mathrm{AX}$ was established as a well-known biomarker and over the last years the $\gamma \mathrm{H} 2 \mathrm{AX}$ assay has come into the focus of attention as a predictive assay. $\mathrm{H} 2 \mathrm{AX}$ is a member of the histone $\mathrm{H} 2 \mathrm{~A}$ family [2]. $\mathrm{H} 2 \mathrm{AX}$ is rapidly phosphorylated after exposure of cells

\footnotetext{
* Correspondence: Luitpold.Distel@uk-erlangen.de

${ }^{\dagger}$ Equal contributors

'Department of Radiation Oncology, Friedrich-Alexander-University of Erlangen-Nürnberg, Universitätsstraße 27, D-91054 Erlangen, Germany Full list of author information is available at the end of the article
}

to ionizing radiation. $\gamma \mathrm{H} 2 \mathrm{AX}$ phosphorylation develops in minutes and reaches its maximum after about $30 \mathrm{mi}$ nutes [3]. The number of DNA DSBs can be directly determined by the number of foci present in the cell shortly after DNA damage [4], since it has been proved that one $\gamma \mathrm{H} 2 \mathrm{AX}$ focus represents one DNA DSB [5]. Rothkamm et al. proclaimed that H2AX phosphorylation and $\gamma \mathrm{H} 2 \mathrm{AX}$ foci formation are now generally accepted as consistent and quantitative markers of DSBs, applicable even under conditions where only a few DSBs are present [5].

The efficiency of $\gamma \mathrm{H} 2 \mathrm{AX}$ detection as a biomarker for DNA DSBs makes this protein a good candidate as a therapeutic marker for improving the efficiency of radiation, drug and other therapies [6-8]. Dickey et al. revealed that $\gamma \mathrm{H} 2 \mathrm{AX}$ is a sensitive indicator of DNA DSBs and is therefore a potentially useful tool in the detection of genotoxic stress. Such an indicator could be valuable in monitoring cancer development and progression as well as other instances of cell stress. Future work in this 
field needs to be directed at moving the $\gamma \mathrm{H} 2 \mathrm{AX}$ detection assay to the clinic where it will be used as a practical means to detect cancer and monitor therapeutic progress [9]. Therefore, the aim of this study was to evaluate the importance of the $\gamma \mathrm{H} 2 \mathrm{AX}$ assay in the detection of rectal cancer patients with remaining $\gamma \mathrm{H} 2 \mathrm{AX}$ foci and a possibly increased radiosensitivity.

\section{Methods}

\section{Study participants}

The prospective study included a total of 195 individuals. Enrolled were 136 rectal cancer patients (RC) and 59 healthy individuals (Figure 1A). All Patients were treated with neoadjuvant radiochemotherapy and total mesorectal excision surgery. Radiotherapy consisted of 50.4 Gy in 28 daily fractions of $1.8 \mathrm{~Gy}$. The patients' age was between 23 and 87 years (Figure 1B) with a mean age of 63.7 years. The age of the control group was between 27 and 80 (Figure 1C) with a mean age of 56.0 years. Table 1 shows an overview of stage and radiotherapeutic and chemotherapeutic treatment of all individuals. This study was approved by the ethics review committees of the Friedrich-Alexander-Universität Erlangen-Nürnberg (No. 2725) and all patients and healthy individuals gave their written informed consent. Blood samples were collected shortly before the first irradiation treatment. Afterwards the patients received a conventional fractionation schedule of radiation $(1.8 \mathrm{~Gy} /$ fraction) up to a total dose of $50.4 \mathrm{~Gy}$.

\section{Immunofluorescence Staining}

Patients and healthy individuals' blood samples were split into three samples. One sample was used as control to detect the spontaneous $\gamma \mathrm{H} 2 \mathrm{AX}$ foci formation. The second sample was ex vivo irradiated with 0.5 Gy X-rays and 30 minutes incubation time and the third one with 2 Gy and 24 hours incubation time. The two different doses were chosen, because a dose of 2 Gy induces after 30 min such a high number of foci that it is not possible to count the foci accurately. On the contrary, with a dose of 0.5 Gy and 24 hours repair the amount of foci is too low to have sufficient foci numbers. Therefore for the initial $\gamma \mathrm{H} 2 \mathrm{AX}$ foci a low and for the remaining $\gamma \mathrm{H} 2 \mathrm{AX}$ foci after 24 hours repair time a high dose was chosen. Peripheral blood mononucleated cells (PBMC) were isolated by Ficoll gradient centrifugation and were cytocentrifuged (StatspinCytofuge, Kreatech, Germany) onto a specimen. The samples were fixed with methanol and acetone and afterwards washed in a phosphatebuffered saline with foetal calf serum. The slides were then incubated with a mouse anti- $\gamma \mathrm{H} 2 \mathrm{AX}$ antibody (Abcam, Cambridge, UK), washed in PBS and incubated with a secondary goat anti-mouse Alexa 488 fluorescent antibody (Molecular Probes, Karlsruhe, Germany).

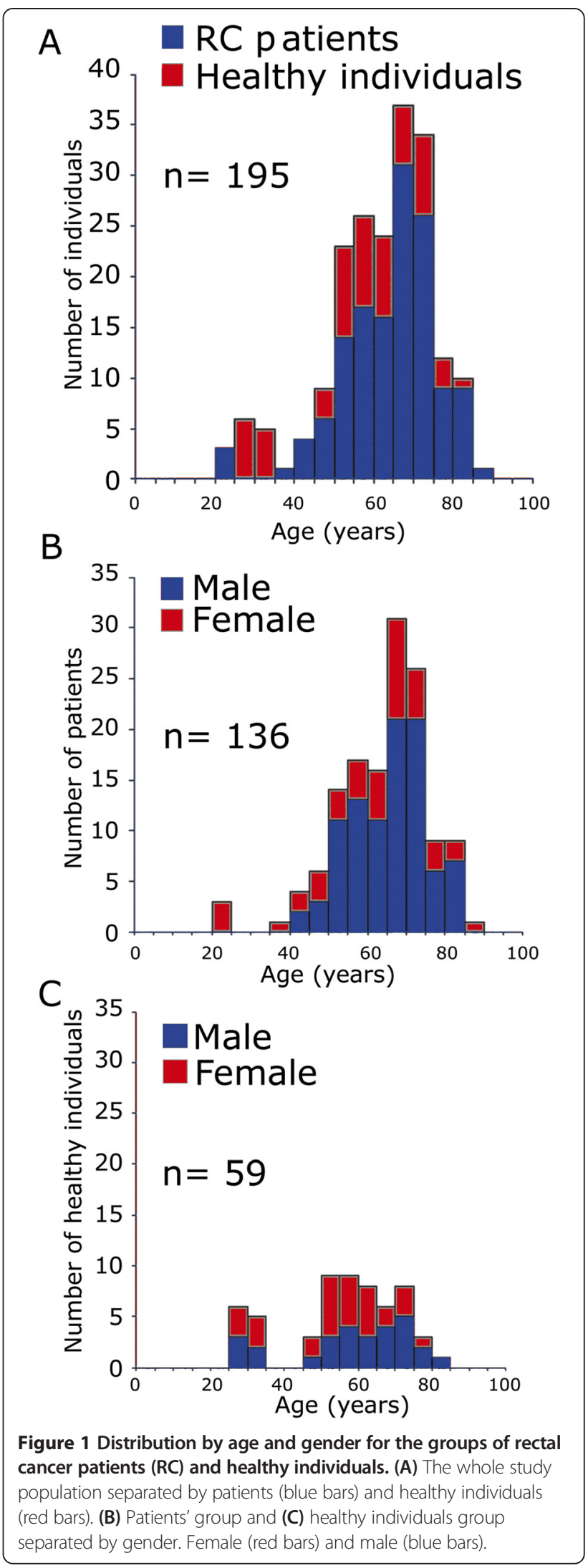


Table 1 Healthy individuals and rectal cancer (RC) patients' characteristics

\begin{tabular}{|c|c|c|c|c|c|c|}
\hline & $\begin{array}{l}\text { Number of } \\
\text { individuals }\end{array}$ & Mean/median age & $\begin{array}{l}\text { Pathologic stage } \\
\text { (UICC) } 1 / 2 / 3 / 4(\%)\end{array}$ & $\begin{array}{l}\text { Chemotherapy 5-FU/5-Fu + } \\
\text { Oxa/Irinotecan/5-FU + } \\
\text { Irinotecan (\%) }\end{array}$ & $\begin{array}{l}\text { Lymph node metastasis } \\
\text { yes/no (\%) }\end{array}$ & $\begin{array}{l}\text { Total RT } \\
\text { dose (Gy) }\end{array}$ \\
\hline Healthy individuals & 59 & $56.0 / 58.5$ & & & & \\
\hline Patients & 136 & $63.7 / 66.0$ & 0/8.1/75.7/16.2 & 25.7/64.5/2.9/3.7 & $89.5 / 10.5$ & 50.4 \\
\hline
\end{tabular}

Afterwards lymphocytes were washed in PBS and mounted with Vectashield mounting medium (Vector Laboratories, Peterborough, UK).

\section{$\mathrm{YH} 2 \mathrm{AX}$ foci recognition}

Fluorescence labelled lymphocytes were visualised by a fluorescence-microscope (Axioplan 2, Zeiss, Göttingen,
Germany) and image acquisition software (Metafer 4, MetaSystems, Altlußheim, Germany). Digital images of five optical planes separated by a distance of $0.75 \mu \mathrm{m}$ were recorded and combined to an extended focus image using the maximum intensity algorithm (Metasystems). An area of $2 \mathrm{~mm}^{2}$ (magnification 630x) was captured automatically. For each of the samples at least

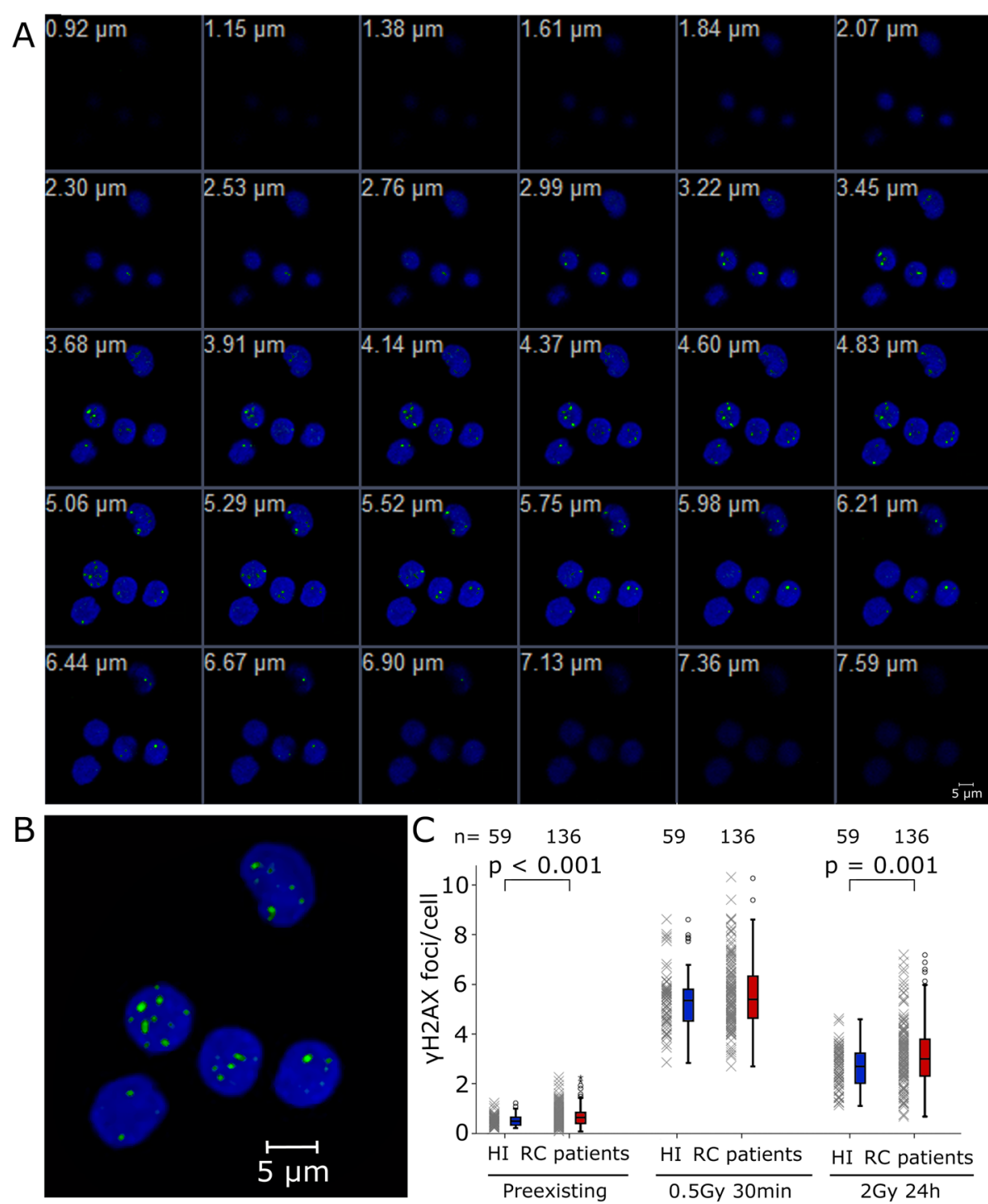

Figure $\mathbf{2}$ Immunostained $\mathbf{\text { H}} \mathbf{2} \mathrm{AX}$ foci in lymphocytes $\mathbf{2 4} \mathbf{~ h}$ post $\mathbf{2 G y} \mathbf{I R}$. (A) $30 \mathrm{z}$-sections with a $0.23 \mu \mathrm{m}$ step size acquired by a laser scanning confocal microscope and (B) a resulting combined extended focus image. (C) Preexisting, initial and remaining $\mathrm{YH} 2 \mathrm{AX}$ foci per cell in 59 healthy individuals ( $\mathrm{HI}$, blue) and 136 rectal cancer patients (red). 


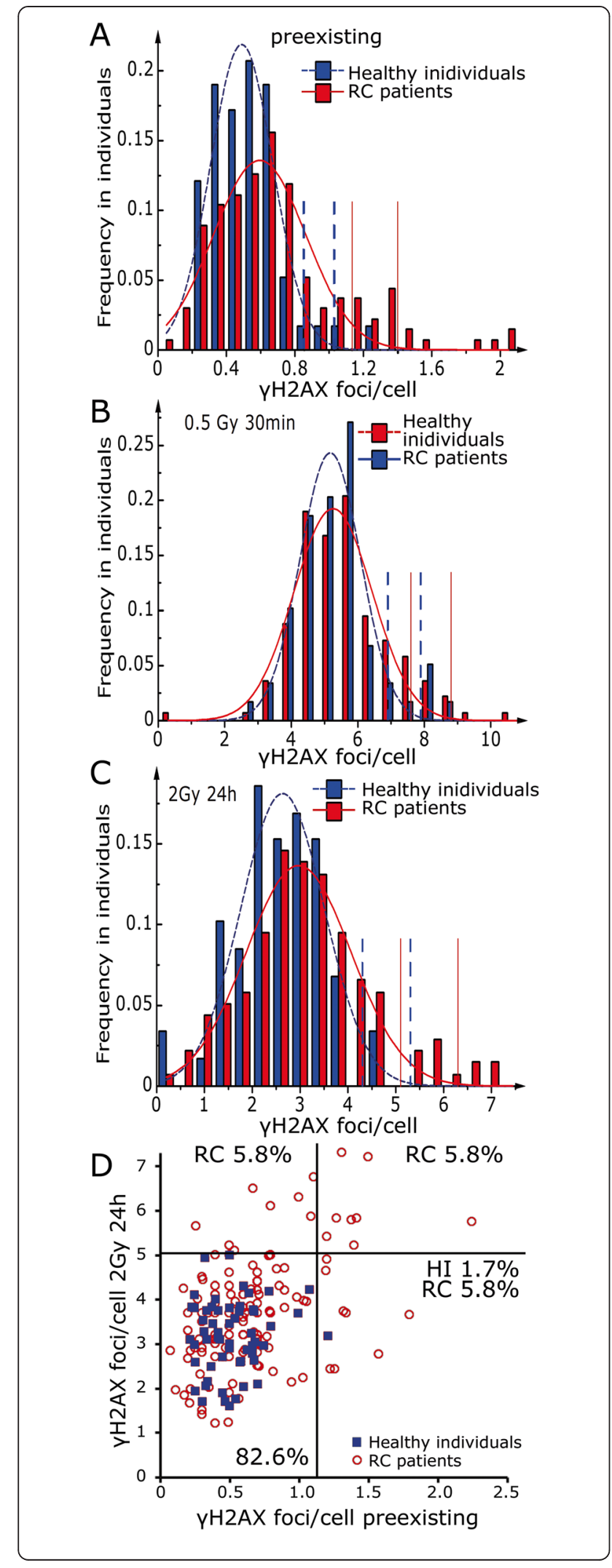

Figure 3 Frequency distribution of the individual $\mathrm{pH} 2 \mathrm{AX}$ foci per cell as measured in ex vivo irradiated lymphocytes after immunostaining. 59 healthy individuals (blue bars) were compared to 136 rectal cancer patients (red bars). The data were fitted using a Gaussian distribution for the (A) preexisting $\mathrm{YH} 2 \mathrm{AX}$ foci, (B) initial YH2AX foci 30 min post IR with $0.5 \mathrm{~Gy}$ (C) remaining $\mathrm{YH} 2 \mathrm{AX}$ foci $24 \mathrm{~h}$ post IR with $2 \mathrm{~Gy}$. Dashed blue vertical lines indicate the value of two and three standard deviations from the mean of the healthy individuals and solid red lines the value of two and three standard deviations from the mean of the RC patients, respectively. (D) Preexisting $\gamma \mathrm{H} 2 \mathrm{AX}$ foci were correlated to remaining $\mathrm{YH} 2 \mathrm{AX}$ foci $24 \mathrm{~h}$ post IR with $2 \mathrm{~Gy} . \mathrm{HI}=$ healthy individuals, $\mathrm{RC}=$ rectal cancer patients.

1000 lymphocytes were identified using image analysis software (Biomas, Erlangen, Germany). All DAPI-stained nuclei were morphologically considered by eye and apoptotic cells were excluded. Using the image analysis software the $\gamma \mathrm{H} 2 \mathrm{AX}$ foci inside each nucleus were counted [10]. The number of mean foci per cell was determined for every individual before irradiation, $30 \mathrm{mi}-$ nutes after 0.5 Gy and $24 \mathrm{~h}$ after 2 Gy ionising radiation (IR). A representative image of $\gamma \mathrm{H} 2 \mathrm{AX}$ foci location in the lymphocytes was acquired by a laser scanning confocal microscope (LSM710, Zeiss, Göttingen, Germany). 30 zsections with a $0.23 \mu \mathrm{m}$ step size were recorded and combined to an extended focus image (Figure 2A, B).

\section{Statistical analysis}

Data analysis and statistics were performed using SPSS 21 for Windows (IBM Corp., Armonk, NY, USA). For comparing the results referred to the different groups, the Kolmogorov-Smirnov test and Lilliefors test were applied for testing normality and data were fitted by a Gaussian distribution. Standard deviations of the Gaussian distributions have been used to designate an individual's categorization. The cut-off values of 2 and 3 standard deviations are equivalent to the $95 \%$ and $99 \%$ confidence intervals. Different groups were compared using the two-sample t-test. Graphics were plotted with TechPlot for Windows 3.0.11 (SFTek, Dr. Ralf Dittrich, Braunschweig, Germany).

\section{Results}

$\gamma \mathrm{H} 2 \mathrm{AX}$ foci rates in a group of $136 \mathrm{RC}$ patients were compared to 59 healthy individuals (Figure 1). Patients' characteristics are described in Table 1. Three samples per patient were analysed. Preexisting $\gamma \mathrm{H} 2 \mathrm{AX}$ foci were compared to initial foci numbers exposed to 0.5 Gy IR and a 30 minutes waiting period. Remaining $\gamma \mathrm{H} 2 \mathrm{AX}$ foci were scored after exposure to 2 Gy IR and 24 hours recovery time.

First it was estimated how many cells had to be counted to obtain reliable $\gamma \mathrm{H} 2 \mathrm{AX}$ rates. The suitable minimum number to yield stable $\gamma \mathrm{H} 2 \mathrm{AX}$ rates was estimated by a Bland Altman analysis. The agreement between the $\gamma \mathrm{H} 2 \mathrm{AX}$ foci rates after every 200 cells was 
estimated. The value indicating an exact agreement would be $100 \%$. Deviations up- and downward are indicated by higher and lower percentages, respectively. A deviation of $\pm 15 \%$ was defined as the range of tolerance. Counting 400 unirradiated lymphocytes, the range for the parameter $\gamma \mathrm{H} 2 \mathrm{AX}$ foci rate was very large. When scoring about 600 lymphocytes, $75 \%$ of the values were within the defined range of tolerance of $\mathrm{z}$ or $\pm 15 \%$ of the 1000 lymphocytes values. By scoring 800 lymphocytes $95 \%$ of the values were within the defined range of tolerance of $\pm 15 \%$. Though a minimum number of 600 lymphocytes were counted and if it was suitable, about 1000 lymphocytes were scored.

The preexisting $\gamma \mathrm{H} 2 \mathrm{AX}$ foci rates in lymphocytes of RC patients' were significantly increased compared to the healthy individuals $(\mathrm{p}<0.001)$. No difference between the two groups was found in initial $\gamma \mathrm{H} 2 \mathrm{AX}$ rates after $0.5 \mathrm{~Gy}$ and 30 minutes incubation time. The residual foci after a dose of 2 Gy and 24 hours recovery time were significantly increased in the $\mathrm{RC}$ patients group compared to the healthy individuals $(\mathrm{p}<0.001)$ (Figure $2 \mathrm{C})$. Additionally in the patients group an increased number of individuals with distinct higher $\gamma \mathrm{H} 2 \mathrm{AX}$ rates was observed. In order to analyse this effect, $\gamma \mathrm{H} 2 \mathrm{AX}$ rates from healthy individuals and patients were classified into suitable divisions of $\gamma \mathrm{H} 2 \mathrm{AX}$ foci per cell and a Gaussian fit was performed. This approach was used to evaluate individuals that distinct fell outside the Gaussian distribution and could be identified as outliers (Figure 3). Using the KolmogorovSmirnov test, the distributions of the patients and healthy individuals were normally distributed, while the more stringent Lilliefors test showed normality for all but the group of preexisting and remaining $\gamma \mathrm{H} 2 \mathrm{AX}$ foci of the healthy individuals. The mean preexisting $\gamma \mathrm{H} 2 \mathrm{AX}$ foci of the RC patients' distribution was increased by $20.4 \%$ compared to the control group (Figure 3A). The mean values of the normal distributions for the initial DNA damage were quite similar (Figure $3 \mathrm{~B}$ ), while the mean residual DNA damage of the RC patients was increased by $13 \%$ (Figure 3C). In the group of RC patients more outliers were observed compared to the controls (Table 2). If we assume a normal distribution, a single value may be considered as an outlier if it falls outside the two or three times the standard deviation. Outside the $2 \times \mathrm{SD}$ of RC patients' Gaussian distribution were exclusively cancer patients. $6 \%$ of the RC patients have increased values in preexisting and remaining $\gamma \mathrm{H} 2 \mathrm{AX}$ foci and $6 \%$ have exclusively increased remaining $\gamma \mathrm{H} 2 \mathrm{AX}$ foci. $5.8 \%$ of the $\mathrm{RC}$ patients and $1.7 \%$ of the healthy individuals had solely increased preexisting $\gamma \mathrm{H} 2 \mathrm{AX}$ foci (Figure 3D).

\section{Discussion}

In this study we compared the preexisting, induced and residual DNA double strand breaks in lymphocytes derived from $136 \mathrm{RC}$ patients and 59 healthy individuals. We found distinct increased values of preexisting and remaining $\gamma \mathrm{H} 2 \mathrm{AX}$ foci in the group of $\mathrm{RC}$ patients. There are clear interindividual differences in both groups and we did find outliers in about $12 \%$ of the RC patients after ex vivo IR. $6 \%$ of the RC patients showed increased numbers of preexisting $\gamma \mathrm{H} 2 \mathrm{AX}$ foci. In the healthy individuals group there was only one individual (1.7\%) with increased preexisting numbers of $\gamma \mathrm{H} 2 \mathrm{AX}$ foci. We could not correlate the measured values with radiotherapy related late effects because of the short period since IR exposure of patients. It is therefore difficult to judge whether the outliers have an increased radiosensitivity and an increased risk of therapy related late effects. Nevertheless, there is an unambiguous difference between the patients group having a distinct increased number of outliers compared to the healthy individuals. We found three different outlier groups (Figure 3D). One group $(n=8)$ has solely increased preexisting $\gamma \mathrm{H} 2 \mathrm{AX}$ foci and no raised values after ex vivo irradiation. We suggest that in this group the values are increased due to an elevated exposure of DNA damaging agents and not to an impaired DNA damage response. The second group $(\mathrm{n}=8)$ are individuals having increased preexisting $\gamma \mathrm{H} 2 \mathrm{AX}$ foci and likewise increased $\gamma \mathrm{H} 2 \mathrm{AX}$ foci after ex vivo irradiation. Here we would argue that patients have an impaired DNA damage response and therefore already raised preexisting $\gamma \mathrm{H} 2 \mathrm{AX}$

Table 2 Percentage of healthy individuals and patients outside of one to three standard deviations from the mean of a Gaussian distribution

\begin{tabular}{|c|c|c|c|c|c|c|}
\hline \multirow{3}{*}{$\begin{array}{l}\text { Group } \\
\text { Distribution } \\
\text { Exposure }\end{array}$} & \multicolumn{2}{|c|}{ Healthy individuals } & \multicolumn{2}{|c|}{ Rectal cancer patients } & \multicolumn{2}{|c|}{ Rectal cancer patients } \\
\hline & \multicolumn{2}{|c|}{ Healthy individuals } & \multicolumn{2}{|c|}{ Rectal cancer patients } & \multicolumn{2}{|c|}{ Healthy individuals } \\
\hline & Preexisting & $2 \mathrm{~Gy}, 24 \mathrm{~h}$ & Preexisting & $2 \mathrm{~Gy}, 24 \mathrm{~h}$ & Preexisting & $2 \mathrm{~Gy}, 24 \mathrm{~h}$ \\
\hline mean & 0.49 & 2.63 & 0.59 & 2.97 & - & - \\
\hline$>1 \times S D$ & $17.2 \%$ & $11.9 \%$ & $21.9 \%$ & $21.2 \%$ & $42.3 \%$ & $33.6 \%$ \\
\hline$>2 \times S D$ & $5.2 \%$ & $3.4 \%$ & $14.6 \%$ & $8.8 \%$ & $22.6 \%$ & $14.6 \%$ \\
\hline$>3 \times S D$ & $3.4 \%$ & $0.0 \%$ & $5.1 \%$ & $2.9 \%$ & $18.2 \%$ & $8.8 \%$ \\
\hline
\end{tabular}

Group defines the used healthy individuals or patients group. Distribution defines the used healthy individual's distribution or the rectal cancer patient's distribution to calculate the percentage of patients outside the one to three standard deviations. Mean is the mean value of the standard deviation. 
foci and as a consequence increased values after ex vivo irradiation. In the third group $(\mathrm{n}=8)$ solely the residual DNA DSB values are raised. Here an impaired DNA damage response may be sufficient to repair the rarely appearing spontaneous DNA damages, however is not sufficient to repair the numerous DNA double strand breaks induced by a dose of 2 Gy. This indicates that the outliers identified by ex vivo irradiation may have an impaired DNA damage response and probably an increased risk to develop radiotherapy related side effects. It is postulated that differences in the repair of DNA DSBs could possibly be related to differences in radiation sensitivity among individuals [11].

Some studies reported an association between $\gamma \mathrm{H} 2 \mathrm{AX}$ foci and individual radiosensitivity. Fleckenstein et al. found a correlation between a serious mucositis and a rising number of foci 24 hours after ex vivo irradiation [12]. Similar Li et al. found that patients with severe oral mucositis had increased remaining damage $24 \mathrm{~h}$ after ex vivo irradiation compared to patients with mild oral mucositis [13]. Another study on a breast cancer patients group with an adverse acute skin reaction (grade 3) to radiotherapy showed significantly increased radiationinduced $\gamma \mathrm{H} 2 \mathrm{AX}$ foci [14]. Additionally the disappearance of the foci was delayed compared to the group of breast cancer patients with normal skin reaction (grade 0-1) [14]. Another study showed clear differences in DNA repair capacity reflected by $\gamma \mathrm{H} 2 \mathrm{AX}$ foci formation in cells from a high proportion of apparently normal individuals using a low dose-rate assay [15]. In addition the persistence of $\gamma \mathrm{H} 2 \mathrm{AX}$ foci after the induction of DNA damage suggests that some of the damage remains unrepaired, which makes $\gamma \mathrm{H} 2 \mathrm{AX}$ an attractive candidate for the rapid assessment of radiation sensitivity in individuals and cell lines [16]. This may lead to the identification of cell lines and human subjects with defective DNA repair $[17,18]$.

On the other hand there have been some studies reporting contradictory results and showing some weakness in the $\gamma \mathrm{H} 2 \mathrm{AX}$ assay. One group stated that $\gamma \mathrm{H} 2 \mathrm{AX}$ focus measurement has limited scope as a pre-RT predictive assay in lymphoblast cell lines from RT patients; however, the assay can successfully identify DNA DSB repair-defective patient's cell lines [19]. Werbrouck et al. concluded from a gynaecological cancer collective that scoring $\gamma \mathrm{H} 2 \mathrm{AX}$ foci in isolated $\mathrm{T}$ lymphocytes after ex vivo irradiation is not predictive for late radiotoxicity [20]. The same authors confirmed in another study that no correlation was found between the $\gamma \mathrm{H} 2 \mathrm{AX}$ foci kinetics and the risk for acute normal tissue complications among patients during IMRT treatment for head and neck cancer [21]. With these contradictory results, Ivashkevich et al. suggested further validation of the assay to show whether the method is specific enough to be predictive in the identification of radiosensitive patients. They also supported the idea that even if the correlation between the assay and clinical radiosensitivity is incomplete, the ability of the assay to detect that subset of radiosensitive patients with defective DNA DSB repair pathways would be valuable per se [22].

There is much hope that the $\gamma \mathrm{H} 2 \mathrm{AX}$ assay has the capability to predict individual radiosensitivity [11,22]. The analysis of chromosomal aberrations has been proved to predict individual radiosensitivity. It is another lymphocyte based assay [23,24] however it takes several days and is work-intensive. The $\gamma \mathrm{H} 2 \mathrm{AX}$ assay can be performed quickly and can also be readily automated [22]. Recently, the automatic analyzes of $\gamma \mathrm{H} 2 \mathrm{AX}$ foci was reported $[25,26]$. Our approach of processing samples is fairly similar, yet with a lower level of automation. The main difference may be that in our system the software marks cells and foci and the user must finally accept or reject these selections. Technical problems with counting foci in the rounded lymphocytes we have overcome by using focal plane merging [27]. We used composite images with an extended depth of field consisting of five optical planes.

\section{Conclusions}

In conclusion the $\gamma \mathrm{H} 2 \mathrm{AX}$ assay has the capability to identify a group of outliers which are probably patients with increased radiosensitivity which have the highest risk suffering from radiotherapy-related late sequelae. Future follow-up on these patients will correlate ex vivo data with clinical outcome.

Competing interests

The authors declare that they have no competing interests.

\section{Authors' contributions}

LVD, CSD, RF and MF conceived of the study and drafted the manuscript. MSschmi carried out dose calculations. JK, BW and MSschw performed the experiments and summarized primary data. CD and MSschw laser scanning image acquisition and aided in carrying out experiments. All authors read and approved the final manuscript.

\section{Acknowledgement}

We thank Doris Mehler and Elisabeth Müller for excellent technical assistance. Additionally we thank all technicians and physicians in the department of radiation oncology for their support of the study. This research was supported by the Dr. Mildred Scheel Stiftung für Krebsforschung grant \#109042 and \#110274. We acknowledge support by Deutsche Forschungsgemeinschaft and Friedrich-Alexander-Universität Erlangen-Nürnberg (FAU) within the funding programme Open Access Publishing.

\section{Author details}

${ }^{1}$ Department of Radiation Oncology, Friedrich-Alexander-University of Erlangen-Nürnberg, Universitätsstraße 27, D-91054 Erlangen, Germany. 2Department of Nephropathology, University Hospitals and Friedrich-Alexander-University Erlangen-Nürnberg Institute of Pathology, 91054 Erlangen, Germany. ${ }^{3}$ Department of Radiation Oncology, University of Würzburg, 97080 Würzburg, Germany.

Received: 21 October 2014 Accepted: 1 February 2015

Published online: 11 February 2015 


\section{References}

1. Torres-Roca JF, Stevens CW. Predicting response to clinical radiotherapy: past, present, and future directions. Cancer Control. 2008;15(2):151-6.

2. Bonner WM, Redon CE, Dickey JS, Nakamura AJ, Sedelnikova OA, Solier S, et al. GammaH2AX and cancer. Nat Rev Cancer. 2008;8(12):957-67.

3. Rogakou EP, Boon C, Redon C, Bonner WM. Megabase chromatin domains involved in DNA double-strand breaks in vivo. J Cell Biol. 1999:146(5):905-16.

4. Sedelnikova OA, Rogakou EP, Panyutin IG, Bonner WM. Quantitative detection of (125)IdU-induced DNA double-strand breaks with gamma-H2AX antibody. Radiat Res. 2002;158(4):486-92.

5. Rothkamm K, Lobrich M. Evidence for a lack of DNA double-strand break repair in human cells exposed to very low x-ray doses. Proc Natl Acad Sci U S A. 2003;100(9):5057-62.

6. Halicka HD, Ozkaynak MF, Levendoglu-Tugal O, Sandoval C, Seiter K, Kajstura $\mathrm{M}$, et al. DNA damage response as a biomarker in treatment of leukemias. Cell Cycle. 2009;8(11):1720-4

7. Kao J, Milano MT, Javaheri A, Garofalo MC, Chmura SJ, Weichselbaum RR, et al. gamma-H2AX as a therapeutic target for improving the efficacy of radiation therapy. Curr Cancer Drug Targets. 2006;6(3):197-205.

8. Kuefner MA, Grudzenski S, Schwab SA, Wiederseiner M, Heckmann M, Bautz W, et al. DNA double-strand breaks and their repair in blood lymphocytes of patients undergoing angiographic procedures. Invest Radiol. 2009;44(8):440-6.

9. Dickey JS, Redon CE, Nakamura AJ, Baird BJ, Sedelnikova OA, Bonner WM. H2AX: functional roles and potential applications. Chromosoma. 2009:118(6):683-92.

10. Endt H, Sprung CN, Keller U, Gaipl U, Fietkau R, Distel LV. Detailed analysis of DNA repair and senescence marker kinetics over the life span of a human fibroblast cell line. J Gerontol A Biol Sci Med Sci. 2011;66(4):367-75.

11. Olive PL, Banath JP. Phosphorylation of histone H2AX as a measure of radiosensitivity. Int J Radiat Oncol Biol Phys. 2004;58(2):331-5.

12. Fleckenstein J, Kuhne M, Seegmuller K, Derschang S, Melchior P, Graber S, et al. The impact of individual in vivo repair of DNA double-strand breaks on oral mucositis in adjuvant radiotherapy of head-and-neck cancer. Int J Radiat Oncol Biol Phys. 2011;81(5):1465-72.

13. Li P, Du CR, Xu WC, Shi ZL, Zhang Q, Li ZB, et al. Correlation of dynamic changes in gamma-H2AX expression in peripheral blood lymphocytes from head and neck cancer patients with radiation-induced oral mucositis. Radiat Oncol. 2013;8:155

14. Djuzenova CS, Elsner I, Katzer A, Worschech E, Distel LV, Flentje M, et al. Radiosensitivity in breast cancer assessed by the histone gamma-H2AX and 53BP1 foci. Radiat Oncol. 2013;8:98.

15. Kato TA, Wilson PF, Nagasaw H, Peng $Y$, Weil MM, Little JB, et al. Variations in radiosensitivity among individuals: a potential impact on risk assessment? Health Phys. 2009;97(5):470-80.

16. Hamasaki K, Imai K, Nakachi K, Takahashi N, Kodama Y, Kusunoki Y. Short-term culture and gammaH2AX flow cytometry determine differences in individual radiosensitivity in human peripheral $T$ lymphocytes. Environ Mol Mutagen. 2007:48(1):38-47

17. Porcedda $\mathrm{P}$, Turinetto $\mathrm{V}$, Brusco A, Cavalieri S, Lantelme E, Orlando L, et al. A rapid flow cytometry test based on histone H2AX phosphorylation for the sensitive and specific diagnosis of ataxia telangiectasia. Cytometry A. 2008;73(6):508-16

18. Taneja N, Davis M, Choy JS, Beckett MA, Singh R, Kron SJ, et al. Histone $\mathrm{H} 2 \mathrm{AX}$ phosphorylation as a predictor of radiosensitivity and target for radiotherapy. J Biol Chem. 2004;279(3):2273-80

19. Vasireddy RS, Sprung CN, Cempaka NL, Chao M, McKay MJ. H2AX phosphorylation screen of cells from radiosensitive cancer patients reveals a novel DNA double-strand break repair cellular phenotype. Br J Cancer. 2010;102(10):1511-8

20. Werbrouck J, De Ruyck K, Beels L, Vral A, Van Eijkeren M, De Neve W, et al. Prediction of late normal tissue complications in RT treated gynaecological cancer patients: potential of the gamma-H2AX foci assay and association with chromosomal radiosensitivity. Oncol Rep. 2010;23(2):571-8.

21. Werbrouck J, Duprez F, De Neve W, Thierens H. Lack of a correlation between gammaH2AX foci kinetics in lymphocytes and the severity of acute normal tissue reactions during IMRT treatment for head and neck cancer. Int J Radiat Biol. 2011;87(1):46-56.
22. Ivashkevich A, Redon CE, Nakamura AJ, Martin RF, Martin OA. Use of the gamma-H2AX assay to monitor DNA damage and repair in translational cancer research. Cancer Lett. 2012;327(1-2):123-33.

23. Distel LV, Neubauer S, Keller U, Sprung CN, Sauer R, Grabenbauer GG. Individual differences in chromosomal aberrations after in vitro irradiation of cells from healthy individuals, cancer and cancer susceptibility syndrome patients. Radiother Oncol. 2006;81(3):257-63.

24. Auer J, Ulrike K, Schmidt M, Ott O, Fietkau R, Distel LV. Individual radiosensitivity in a breast cancer collective is changed with the patients age. Radiol Oncol. 2014;48(1):80-6.

25. Runge R, Hiemann R, Wendisch M, Kasten-Pisula U, Storch K, Zophel K, et al. Fully automated interpretation of ionizing radiation-induced gammaH2AX foci by the novel pattern recognition system AKLIDES(R). Int J Radiat Biol. 2012;88(5):439-47.

26. Willitzki A, Lorenz S, Hiemann R, Guttek K, Goihl A, Hartig R, et al. Fully automated analysis of chemically induced gammaH2AX foci in human peripheral blood mononuclear cells by indirect immunofluorescence. Cytometry A. 2013;83(11):1017-26.

27. Goodarzi AA, Jeggo PA. Irradiation induced foci (IRIF) as a biomarker for radiosensitivity. Mutat Res. 2012;736(1-2):39-47.

\section{Submit your next manuscript to BioMed Central and take full advantage of:}

- Convenient online submission

- Thorough peer review

- No space constraints or color figure charges

- Immediate publication on acceptance

- Inclusion in PubMed, CAS, Scopus and Google Scholar

- Research which is freely available for redistribution 